\title{
The effect of temporal and spatial variation of harmonic sources on annual harmonic performance of distribution networks
}

DOI:

10.1109/ISGTEurope.2014.7028848

\section{Document Version}

Accepted author manuscript

Link to publication record in Manchester Research Explorer

Citation for published version (APA):

Abdelrahman, S., \& Milanovic, J. (2014). The effect of temporal and spatial variation of harmonic sources on annual harmonic performance of distribution networks. In host publication IEEE.

https://doi.org/10.1109/ISGTEurope.2014.7028848

\section{Published in:}

host publication

\section{Citing this paper}

Please note that where the full-text provided on Manchester Research Explorer is the Author Accepted Manuscript or Proof version this may differ from the final Published version. If citing, it is advised that you check and use the publisher's definitive version.

\section{General rights}

Copyright and moral rights for the publications made accessible in the Research Explorer are retained by the authors and/or other copyright owners and it is a condition of accessing publications that users recognise and abide by the legal requirements associated with these rights.

\section{Takedown policy}

If you believe that this document breaches copyright please refer to the University of Manchester's Takedown Procedures [http://man.ac.uk/04Y6Bo] or contact uml.scholarlycommunications@manchester.ac.uk providing relevant details, so we can investigate your claim.

\section{OPEN ACCESS}




\title{
The Effect of Temporal and Spatial Variation of Harmonic Sources on Annual Harmonic Performance of Distribution Networks
}

\author{
Sami Abdelrahman, Huilian Liao and Jovica V. Milanović \\ University of Manchester, Manchester, UK \\ Sami.abdelrahman@postgrad.manchester.ac.uk,milanovic@manchester.ac.uk
}

\begin{abstract}
The increasing penetration of converter connected distributed generation and the electric vehicles in today's distribution network, introduce new uncertainties to the harmonic performance evaluation. The common practice of day/week evaluation of harmonics may not be feasible for long term planning applications due to the spatial (EV) and temporal (DG) variation in harmonic sources. This paper proposes a probabilistic methodology to evaluate the annual harmonic performance of distribution network, considering the uncertainties involved due to the connection of distributed generation and electric vehicles including their temporal and spatial variation.
\end{abstract}

Keywords: Harmonics, THD, Probabilistic, Monte Carlo, DG

\section{INTRODUCTION}

The increasing DG penetration in today's distribution networks has different impacts on the networks. Some questions may arise here; will the DG connection have a positive or negative impact? Which aspects of Power Quality (PQ) are impacted? What penetration level is significant? These questions motivate investigating the overlap between the PQ performance and the DG [1].

One of the main concerns of increased DG is the impact on the PQ performance of network. Phenomena like voltage regulation, unbalance and harmonics will be affected by the DGs connection, effects that typically were not considered during the planning stage of distribution network. Different types of DG can have different impacts on PQ. The intermittent photovoltaic (PV) and wind generators can lead to voltage fluctuations. The connection interface like power electronic converters can increase the harmonic levels in the network. The DG can cause overvoltage during light load periods but also it can support the voltage during the voltage sag events. Different penetration levels and locations have different impact. In general a penetration level up to $15 \%$ of the feeder capacity will not lead to significant negative impacts. This ratio drops to $5 \%$ in case of long feeder, and can increase to up to $30 \%$ of the feeder capacity in case the DG connections are close to the substation [1].

The main causes of harmonics in power networks are nonlinear loads and devices supplied with switch-mode power supplies, and more recently power electronic interfaced generators. The harmonics can have both momentary impacts on the network like mal-operation of protection systems and contactors, or long run impacts like reduced life time of equipment [2]. The general methodology for calculating the system harmonic indices can be divided into three steps; calculating the different spectra of the voltage and currents over a window of time, calculating the required indices from the spectra for different sites, and then calculating the total system indices from the sites indices [3]. Several indices are developed to describe the harmonics phenomenon; the most common indices are the Total Harmonic Distortion (THD) for the voltages and currents and can be calculated by (1) and (2),

$$
\begin{gathered}
T H D_{V}=\sqrt{\sum_{h=2}^{\infty} V_{h}^{2}} / V_{1} \\
T H D_{I}=\sqrt{\sum_{h=2}^{\infty} I_{h}^{2}} / I_{1}
\end{gathered}
$$

where $h$ is the harmonic number, $V_{h}$ and $I_{h}$ are the harmonic voltages and currents, and $V_{l}$ and $I_{l}$ are the fundamental voltage and current [4]. Other harmonic indices are developed for more specific applications; the Total Demand Distortion $T D D$ was developed to describe the harmonic performance in case of low fundamental current, where the THD could be misguiding. Also telephone interference factor was developed to describe the harmonic performance when it affects the audio and communication system (high harmonics orders). The $\mathrm{K}$ Factor index to describe the de-rating of transformers under the harmonics presence, and also the zero crossing factor to describe the impact of harmonics in the equipment that works on the concept of waveform changing from positive to negative or vice versa (e.g. contactors and electronic clocks) [5].

The impact of the DG on the harmonic performance is presented in [6] focusing on the interactions between DG invertors' emissions and the grid background harmonic pollutions. Similarly, [7] investigated the impact of wind turbine on the harmonic performance, especially in the cases where the wind generators are connected with the power factor correction capacitors and causing a resonance problem at the point of connection. Also, the impact of the PV and storages connections on a distribution feeder was studied in [8], the phenomena of voltage regulation, unbalance and harmonics were analysed under different levels of DG penetration.

This paper presents a methodology for probabilistic assessment of annual harmonic performance of the network

This work is supported by EU FP7 Project SuSTAINABLE Grant No. 308755 S. Abdelrahman, H. Liao and J.V. Milanović are with the School of Electrical and Electronic Engineering, The University of Manchester, PO Box 88, Manchester, M60 1QD, UK. (email: milanovic@ manchester.ac.uk). 
considering the main uncertainties involved in the spatial and temporal variations of harmonics sources, such as the harmonics injections, output of the DG, and the locations of the non-linear loads (e.g. electric vehicles). The study focuses in the DG impact on the harmonics performance, trying to quantify the impact both on the whole system and individual buses. Statistical comparison was performed between the harmonics indices of the system and the compatibility limits recommended by the IEEE and IEC standards. Heat maps are used to identify the weak areas of the network in terms of harmonics performance. The methodology is demonstrated on a 295 bus generic distribution network.

\section{EVALUATION OF HARMONICS}

Two levels of harmonic performance are usually determined and compared to standards; the planning levels and the compatibility levels [9]. The planning levels, as the name implies, are usually for the planning purposes, the utility set these limits as internal targets and objectives considering the supply and consumers emissions (DG was usually not considered in the traditional "fit-and-forget" planning approach). The planning levels are typically lower or equal to the compatibility levels. They are difficult to determine as they vary from network to network based on the structure, location, importance, etc. On the other hand, the compatibility levels are the reference values to set the immunity of the system equipment (network and users) to ensure the electromagnetic compatibility between the emission levels and equipment connected [9]. The compatibility levels are usually calculated for the whole system statistically ( $95 \%$ probability levels) considering a distribution that covers the temporal and spatial variations of the phenomenon [9].

TABLE I: Harmonics voltage limits in IEEE and IEC standards

\begin{tabular}{|c|c|c|c|}
\hline $\begin{array}{c}\text { Harmonic } \\
\text { order (h) }\end{array}$ & $\begin{array}{c}\text { Comp. levels } \\
\text { (IEC 61000-2-12) }\end{array}$ & $\begin{array}{c}\text { Planning } \\
\text { levels (IEC } \\
\mathbf{6 1 0 0 0 - 3 -} \\
\mathbf{6 : 1 9 9 6}[\mathbf{9}])\end{array}$ & $\begin{array}{c}\text { Voltage limits } \\
\text { (IEEE 519:1992 } \\
{[\mathbf{4}] \text { ) }}\end{array}$ \\
\hline 3 & 5 & 4 & 3 \\
\hline 5 & 6 & 5 & 3 \\
\hline 7 & 5 & 4 & 3 \\
\hline 9 & 1.5 & 1.2 & 3 \\
\hline 11 & 3.5 & 3 & 3 \\
\hline 13 & 3 & 2.5 & 5 \\
\hline THD & 8 & 6.5 & \\
\hline
\end{tabular}

The main steps for the evaluation process, recommended by the IEC standard [9], are summarized in the following points;

- Calculate the spectrum over a 10 cycle period (for $50 \mathrm{~Hz}$ system), considering synchronization of the assessment window with the actual frequency.

- $\quad$ The RMS values of the obtained spectrum are aggregated over a 3 seconds periods to create the 'very short time index' $\left(V_{h, v s}\right)$.

- The 3-seconds RMS values are then aggregated into a 10minutes value, which gives the 'short time' index $\left(V_{h, s h}\right)$.

- The 'short time' and 'very short time' indices are evaluated over longer periods of study, typically a day or a week.
The calculated indices should be described statistically; the $95 \%, 99 \%$ or the maximum value can be used to describe the site performance [3]. More details about calculation methodology and measurements procedure can be found in [9] and [10], respectively. Table I gives a comparison between the limits of the harmonic voltage indices in the IEEE and IEC standards and between the compatibility and planning level in the IEC standards for selected harmonics (adopted from [3]).

\section{TEST SYSTEM}

The test network used in these studies is the 295 bus Generic Distribution Network (GDN). The network parameters are based on realistic UK distribution network parameters [11, 12]. The network consists of 295 buses, 276 branches (overhead lines and cables), and 37 transformers with various winding connections. The network comprises five $400 \mathrm{kV}$ buses, and four $275 \mathrm{kV}$ buses (transmission level connection points) a sub-transmission level of twenty-three $132 \mathrm{kV}$ buses and twenty-five $33 \mathrm{kV}$ buses, and a distribution level of 233 buses of $11 \mathrm{kV}$ level and four $0.4 \mathrm{kV}$ buses. Detailed description and parameters of the network can be found on [13].

\section{MODELLING OF HARMONIC SOURCES}

\section{A. Load}

The total load of the test network is $376.86 \mathrm{MW}$ and 77.35 MVAr distributed among the sub-transmission level and the distribution levels (49.25 MW and 3.22 MVAr connected at the $11 \mathrm{kV}$ level). The loads were divided into three types, industrial, commercial and domestic. 147 buses have a combination of $80 \%$ domestic and $20 \%$ commercial load, and 3 buses are dedicated as industrial loads only. Annual hourly loading curves were extracted from 2010 survey of different types of loads, and applied to each load in the network. Out of the 150 loads a group of 30 loads is selected as harmonic sources, i.e. non-linear loads. Out of these, 10 non-linear loads have fixed locations and the remaining 20 are selected at random locations in the network at every simulation hour (as it will be detailed in section V).

According to [14], non-linear loads injections depend on the rating and the operating condition. Non-linear loads can perform steadily (fluorescent lamps), can perform deterministically (battery chargers), and some can perform randomly (arc welders). Also, [14] categorized the non-linear loads into four categories for probabilistic harmonics modelling; constant number of known injections loads; random number of known injections loads; constant number of random injections loads; random number of random injections loads [14]. The study presented in this paper can be considered as the third category (constant number of random injections loads); however, although the number of loads in this study is kept constant their locations are varied randomly every hour.

Two classes of non-linear loads are adopted, the first is dominated by the 3rd, 5th, 7th and 9th harmonic currents, e.g., personal computers, TV set, fluorescent lamps etc. [5]. This type of harmonic spectra was used for domestic and commercial non-linear loads. The second load class, for the industrial loads, e.g., three-phase adjustable speed drives, the 
harmonic spectra is mainly dominated by the $3 \mathrm{rd}, 5$ th, 7 th and 11th harmonic [5].

Table II shows the average value of current injections for individual harmonics for each class of load (adopted from [5]). The random injections are modelled as normally distributed functions with $\pm 20 \%$ range around the mean values shown in Table II. This probabilistic representation is implemented to cater for the uncertainties involved in the harmonics injections of composite loads, such as different operating conditions, different loading levels, different ratio of non-linear/linear loads at the bus, etc.

TABLE II: Harmonic currents average amplitude of non-linear loads (adopted from [5])

\begin{tabular}{|c|c|c|}
\hline $\begin{array}{c}\text { Harmonic } \\
\text { order }\end{array}$ & $\begin{array}{c}\text { Type 1 (Domestic } \\
\text { and Commercial) }\end{array}$ & $\begin{array}{c}\text { Type 2 } \\
\text { (Industrial) }\end{array}$ \\
\hline 1 & $100 \%$ & $100 \%$ \\
\hline 3 & $69 \%$ & $4.7 \%$ \\
\hline 5 & $48 \%$ & $32 \%$ \\
\hline 7 & $28 \%$ & $16 \%$ \\
\hline 9 & $27 \%$ & $0 \%$ \\
\hline 11 & $0 \%$ & $6.5 \%$ \\
\hline
\end{tabular}

\section{B. Distributed Generators}

The DGs are connected at twenty-five different buses. The buses were chosen to cover all different locations which might have effects on the performance of the network, i.e., at the start of a feeder (close to the MV/LV sub-station), in the middle of a feeder and at the end of a feeder. The maximum DG penetration is around $30 \%$ of the peak loading of the 7 $33 / 11 \mathrm{kV}$ transformers (labeled C, D, H, I, J, K and L in Fig. 5) based on the recommendations given in $[1,8]$ regarding the maximum accepted level of DG penetration. Even though during some low load periods and high DG output, the DG output reached up to $60 \%$ of the demand at that period but no hosting capacity or reverse power problems were noted.

Three types of DG were considered, wind generators, photovoltaic and fuel cells. The wind generators were modelled as three phase asynchronous generators of DFIG type. The fuel cells and most of the photovoltaic generators were modelled as single phase static generators connected via 6 pulse converters. Two PV parks are modelled as static generators connected via three phase 6-pulse convertors. The annual hourly output curves for the wind and photovoltaic generators were extracted from realistic output data based on the UK weather $[15,16]$ (the maximum output of these two types of DGs is at different times of the year) while the fuel cells were assumed to have a constant output.

TABLE III: Harmonic currents average amplitude of DG

\begin{tabular}{|c|c|c|}
\hline $\begin{array}{c}\text { Harmonic } \\
\text { order }\end{array}$ & Wind Gen. & PV/Fuel Cells \\
\hline 1 & $100 \%$ & $100 \%$ \\
\hline 5 & $1.9 \%$ & $0.16 \%$ \\
\hline 7 & $0.4 \%$ & $0.18 \%$ \\
\hline 11 & $0.1 \%$ & $0.12 \%$ \\
\hline 13 & $0.1 \%$ & $0.11 \%$ \\
\hline
\end{tabular}

The wind generators (five in total) have total maximum output 2.28 MW (comprising units with rating from 0.42 to 0.6 MW). Ten PV generators have total maximum output of 4.31 MW (vary from 0.15 to $1.7 \mathrm{MW}$ ). Ten fuel cells have a constant output of 8.69 MW in total. Assuming same geographical conditions for all DG locations all PV units and wind generators are assumed to have the same output during the same hours. The fuel cells are assumed to be available at full capacity during the whole year. All DG units work at unity power factor, with no voltage controllers applied. The harmonic injections (see Table III) of the DG are modelled as normally distributed functions around mean values extracted from commercial convertors test sheets [17] for the PV and fuel cells and from [7] for the DFIG.

\section{METHODOLOGY}

The proposed methodology for the annual harmonic performance evaluation is based on selecting a number of testing hours during a year, and running Monte Carlo simulations at these selected hours. Focusing on the impact of the DG on the harmonics performance, ten testing hours were selected from the cumulative output curve of the DG, shown in Fig 1. The output curve was segmented equally into ten segments. The maximum point of each segment was taken as a testing hour, for example, the first segment of the maximum DG penetration during the year occurred at the $2773^{\text {rd }}$ hour of the year (Monday 1 p.m. in April), in this hour the output of the PV was 0.95 p.u. (total of $4.1 \mathrm{MW}$ ), the output of the wind generators was 0.98 p.u. (total of $2.23 \mathrm{MW}$ ) and the output of the fuel cells, as it is constant during the year, was 1 p.u. (total of 8.69 MW). The minimum penetration of the DG during the year (Thursday 8 p.m. in November) is about 0.58 p.u. and it is contributed to by the fuel cells only.

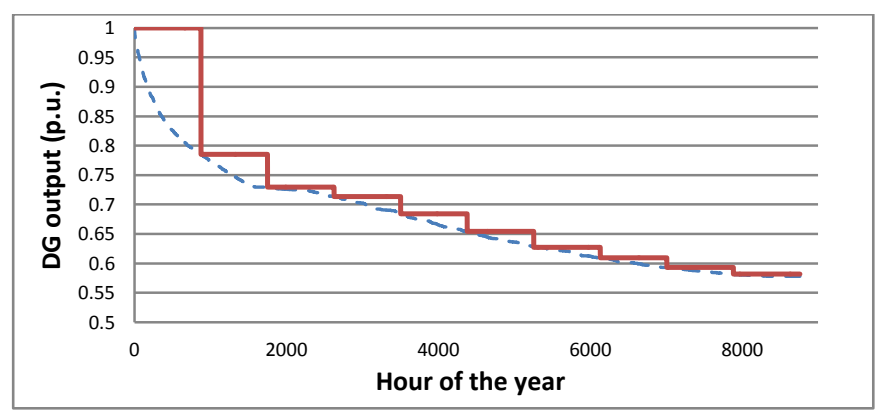

Fig. 1. The accumulated DG output curve, continuous (blue, dashed), piecewise (red, solid)

The selected testing hours covered the seasonality of the DG to a large extent. In order to isolate and measure the impact of the DG on harmonics the different load types were kept around the same values in all the testing hours. The second assessment method was hour-by-hour harmonic injection for a single day with the same models of DGs and non-linear loads as in the annual simulations method. A summer day (high PV output) was selected and the simulations were run for the 24 hours of that day with the same number of simulations per hour. This assessment method was used in order to compare the annual performance and the daily performance of a bus and the effect of seasonality on the bus harmonics performance.

In every Monte Carlo simulation, there were maximum 55 harmonic sources at different buses, i.e., 25 DG units in 
addition to 30 non-linear loads (some DG units though had 0 output during some simulation hours). Out of 30 non-linear loads, locations of 20 of them were selected randomly in every test hour. All the harmonic sources are modelled as current sources at different frequencies; the ratios of each harmonic currents to the fundamental currents were sampled from normal distributions around the mean values shown in tables II and III for different types of loads and DG. The angles of the injected currents were randomly selected from uniform distribution ranges from 0 to 180 degrees. The harmonic load flow was performed using DIgSILENT PowerFactory (v15.0.1). For each testing hour 300 simulations were run to minimise computational burden even though according to [9] 3000 measurements are required to calculate $V_{h, s h}$ (one measurement every 10 cycles for 10 minutes for $50 \mathrm{~Hz}$ systems).

Based on these simulations the mean value and the $95^{\text {th }}$ percentile of $T H D_{V}$ and $V_{h}$ for each phase at every bus were recorded throughout the year and for the selected day. The simulations were run for the cases with and without DGs connected to the network.

\section{RESULTS}

For all the results shown in this section phase A was taken as the case study, unless otherwise clearly identified. The mean and the $95^{\text {th }}$ percentiles were chosen to represent all the results statistically. Normal distribution was used to represent the results, even though it is not the best fit in some cases. It was selected due to simplicity and clarity of the comparison.

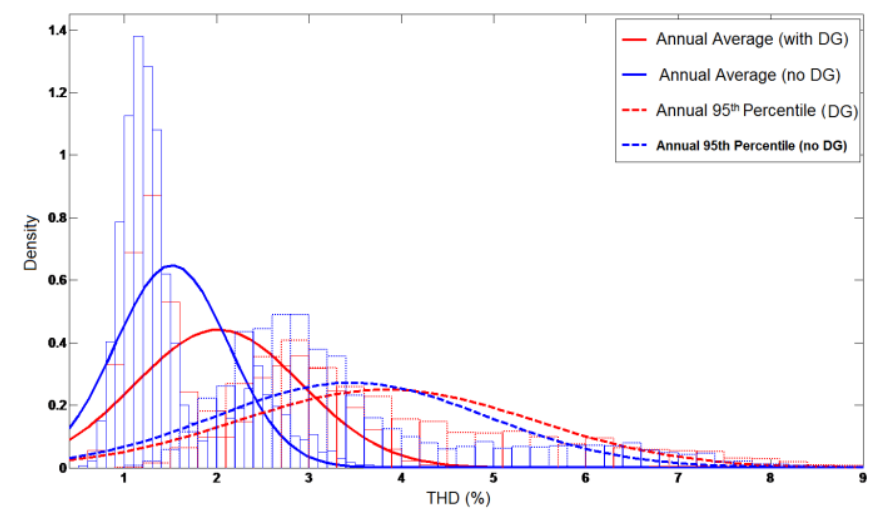

Fig. 2. Annual THD system performance average values (solid) and percentile values (dashed), before (blue) and after (red) DG connection

The overall system annual performance in terms of THD, before and after the connection of DG, is shown in Fig. 2. As it can be seen, the overall impact of the DG can be considered insignificant, the average of THD mean values for all buses has increased from $1.5 \%$ to $2 \%$, and the average of the $95^{\text {th }}$ percentile values of all buses has increased from $3.45 \%$ to $3.84 \%$. However, the overall impact can be misguiding in judging the network performance as the increase in the THD was not evenly distributed between buses. Some buses are affected more than the rest of the network after the connection of the DG, showing an increase of the average THD up to $1.5 \%$ at some buses, and increase of the $95^{\text {th }}$ percentile values of THD up to almost $6 \%$, Fig 3 (a) and (b) show these

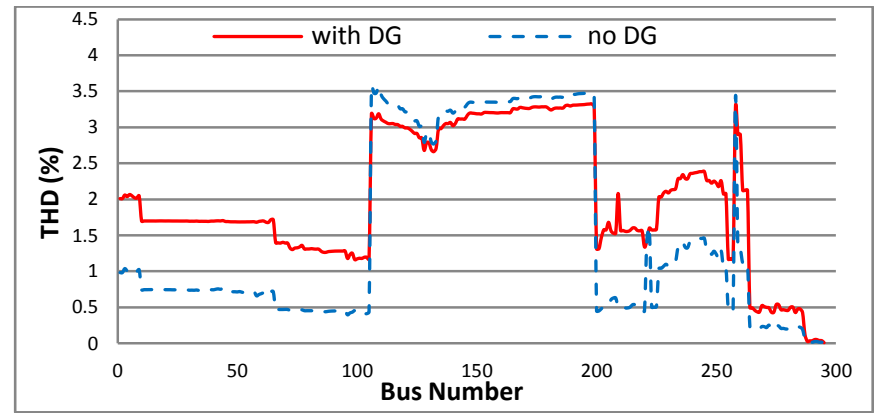

(a) Average values

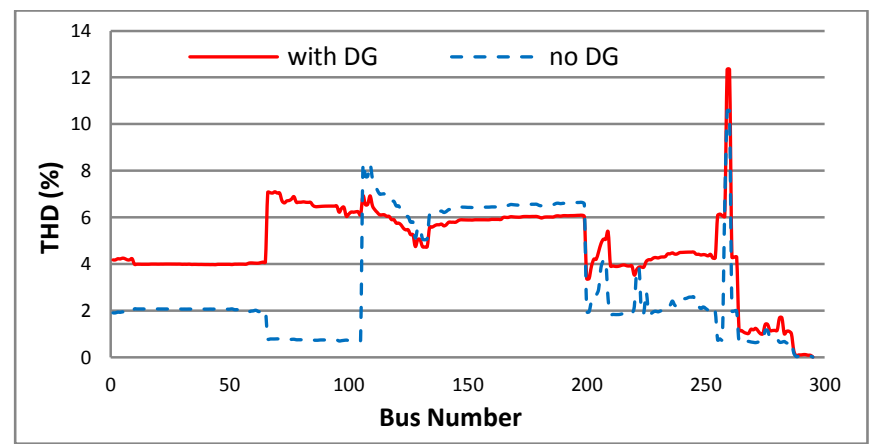

(b) Percentile values

Fig. 3. Average (a) and $95^{\text {th }}$ percentile (b) THD for all the buses before (blue/dashed) and after (red/solid) DG connection

comparisons in terms of average and $95^{\text {th }}$ percentile THD. From Fig. 3 it can be seen that all the buses with exception of buses $66-100$ follow the same trend in the THD values before and after the connection of DGs. For Buses 66 - 100 the increase in the percentile values is much higher than the increase in the average value of THD. This is due to the fact that the percentile measure is more affected by the extreme values obtained during the MC process than the average measure. It can be also seen from Fig 3 that some buses showed better performance after the connection of the DG. This could be a result of adding harmonic sources injecting the same harmonic currents at different angles which led to harmonic cancellation.

TABLE IV: The most affected buses performance (a) Average THD

\begin{tabular}{|c|c|c|c|c|c|}
\hline \multicolumn{6}{|c|}{ THD } \\
\hline \multicolumn{2}{|c|}{ A } & \multicolumn{2}{c|}{ B } & \multicolumn{2}{c|}{ C } \\
\hline bus & $\%$ & bus & $\%$ & bus & $\%$ \\
\hline 178 & 3.32 & 178 & 3.3 & 178 & 3.12 \\
\hline 177 & 3.32 & 177 & 3.3 & 177 & 3.12 \\
\hline 176 & 3.32 & 176 & 3.3 & 176 & 3.12 \\
\hline 175 & 3.32 & 175 & 3.29 & 175 & 3.11 \\
\hline 174 & 3.31 & 174 & 3.29 & 174 & 3.11 \\
\hline
\end{tabular}

(b) $95^{\text {th }}$ Percentile THD

\begin{tabular}{|c|c|c|c|c|c|}
\hline \multicolumn{7}{|c|}{ THD } \\
\hline \multicolumn{2}{|c|}{ A } & \multicolumn{2}{c|}{ B } & \multicolumn{2}{c|}{ C } \\
\hline bus & $\%$ & bus & $\%$ & bus & $\%$ \\
\hline 36 & 7.1 & 137 & 7.21 & 137 & 6.78 \\
\hline 35 & 7.07 & 138 & 7.21 & 138 & 6.78 \\
\hline 34 & 7.06 & 136 & 6.85 & 71 & 6.69 \\
\hline 31 & 7.05 & 135 & 6.85 & 66 & 6.68 \\
\hline 33 & 7.05 & 134 & 6.77 & 69 & 6.66 \\
\hline
\end{tabular}




\section{$>$ ACCEPTED VERSION OF THE PAPER <}

Table IV (a) and (b) show the worst five performing buses at the $11 \mathrm{kV}$ level, in terms of average and $95^{\text {th }}$ percentile THD, respectively. The ranking based on the annual average THD is more consistent between phases while the ranking based on the $95^{\text {th }}$ THD percentile shows discrepancy between phases. The worst five buses based on the average values do not appear in Table IV (b). The most affected phases (based on the percentile measure) at critical buses are depicted in Fig.4.

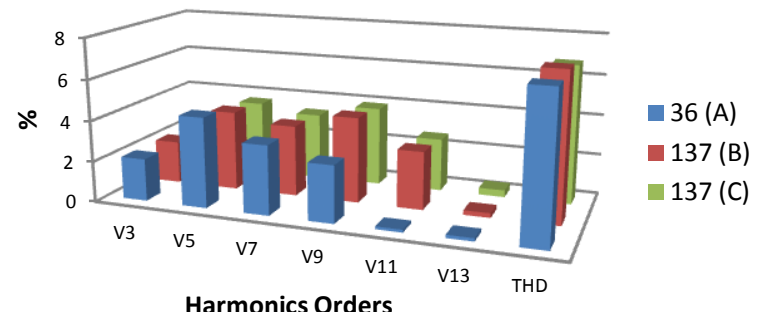

Fig. 4. Harmonics orders and THD percentiles for the most affected buses

Fig. 4 can be used to determine which harmonic orders have more effect on the total distortion for a certain bus, i.e. the harmonic currents that propagate through the higher harmonic impedances seen from the bus under study. It also can be used to give indications about the orders and locations of the harmonic mitigation solutions if required.

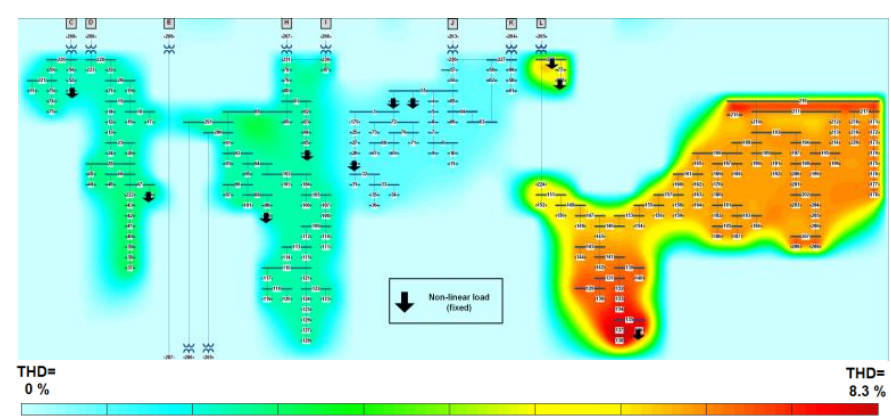

(a) Harmonic performance without DG

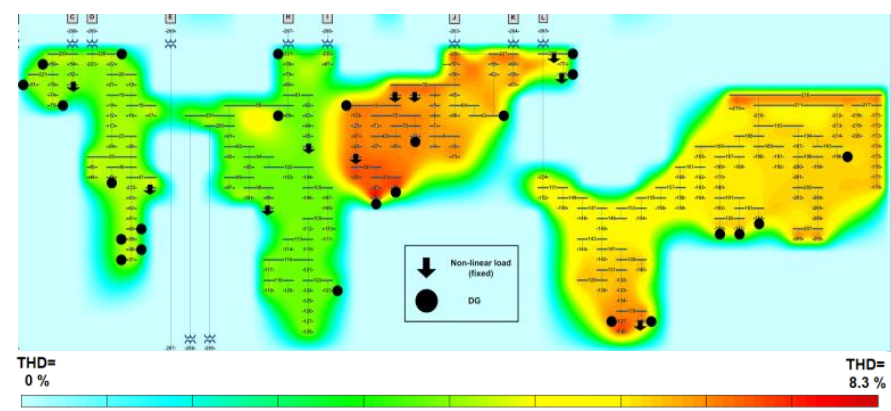

(b) Harmonic performance with DG

Fig. 5. Heat Maps of the $95^{\text {th }}$ percentile THD for $11 \mathrm{kV}$ buses

Fig. 5 (a) and (b) show the percentiles values of THD for all the $11 \mathrm{kV}$ buses before and after the connection of DG using heat maps. It can be seen that the feeder from substation $\mathrm{L}$ (the utmost right substation) showed similar performance before and after the connection of DG, while the rest of the network showed various level of increased THD. Also, to study the effects of the hourly variation of DG during one day, heat maps were plotted at 03:00 a.m. and 09:00 a.m. on a summer day, Fig. 6 (a) and (b) show the heat maps at these hours. (Note: The scale for colour coding in these three figures is different due to different THD ranges.)

Heat maps were also used to pinpoint the areas where violations of the standard limits occurred, showing only the buses where IEEE standard [4] limits were violated (see Table I). Fig. 7 (a) shows the areas where the $5^{\text {th }}$ harmonic voltage exceeded the limit, while Fig. 7 (b) shows the areas where the THD exceeded the limit. This way of representing the performance of the network facilitates easy identification of the critical harmonics and locations requiring attention.
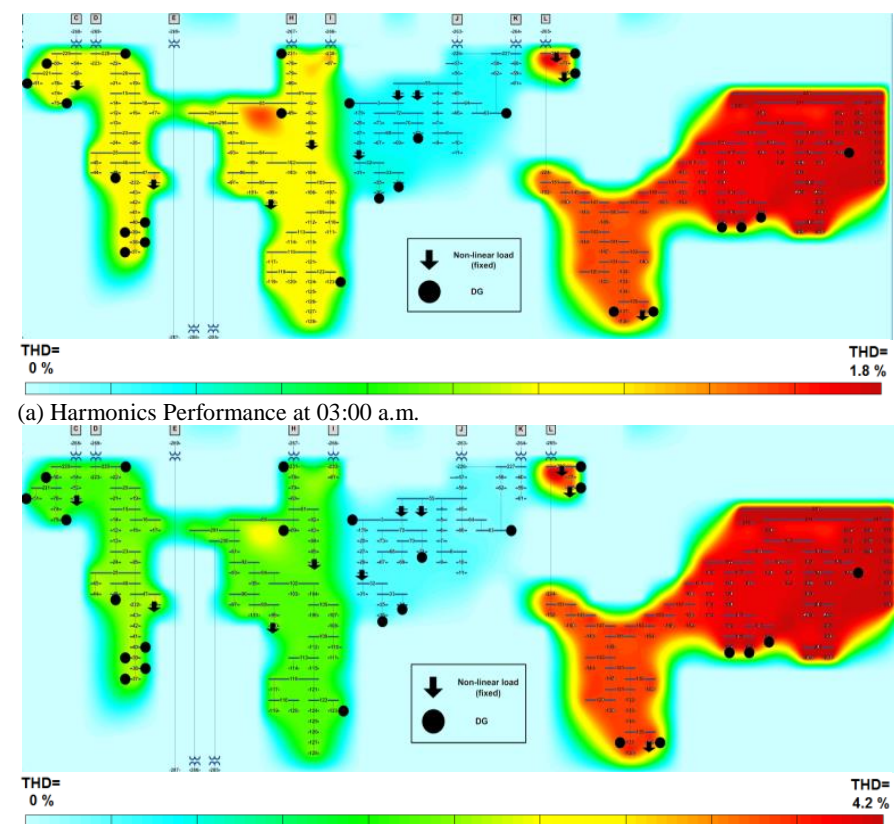

(b) Harmonics Performance at 09:00 a.m.

Fig. 6. Heat Maps for different hours during a day
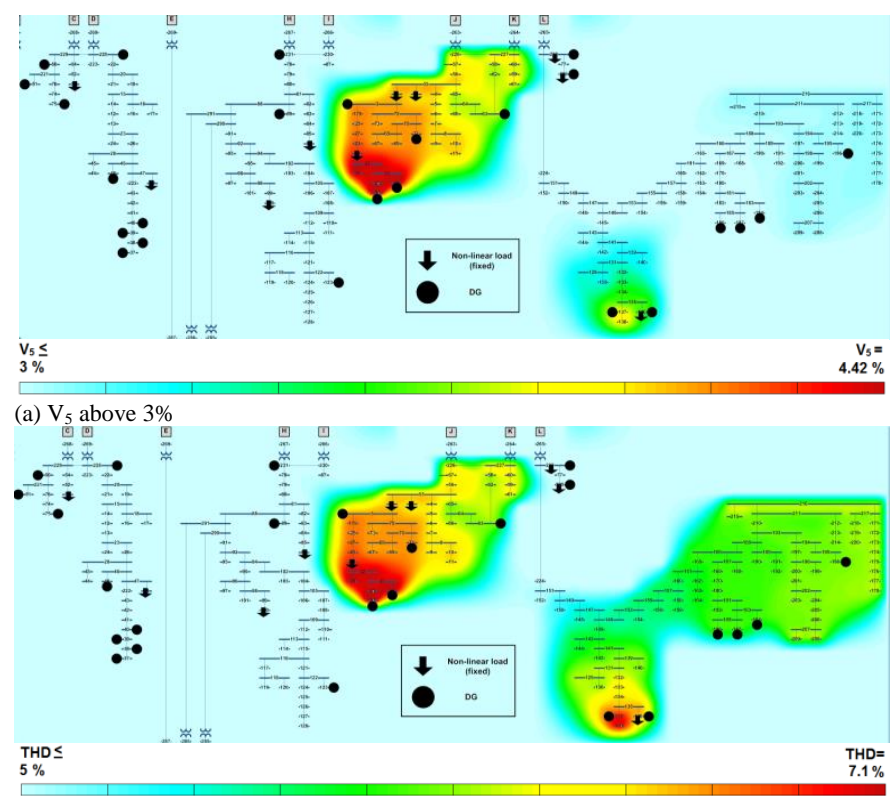

(b) THD above $5 \%$

Fig. 7. Heat Maps for the areas that violated the IEEE standard limits. 


\section{CONCLUSION}

This paper presented a methodology to perform annual harmonic performance evaluation of distribution networks with temporal and spatial variation of harmonic sources. Uncertainties due to harmonics sources changing locations (i.e., electric vehicles), and due to highly variable, intermittent harmonics sources (i.e. DG) were considered in this methodology using Monte Carlo simulations.

In order to quantify the impact of the DG, a conservative DG penetration of about $30 \%$ was simulated. The results showed that even though the overall increase in harmonics in the network is insignificant some buses experienced more than $100 \%$ increase in THD.

\section{REFRENCES}

[1] M. F. M. Roger C. Dugan, Surya Santoso, H. Wayne Beaty, Electrical Power Systems Quality, 2nd ed. New York: McGraw-Hill, 2002.

[2] G. J. Wakileh, Power Systems Harmonics: Fundamentals, Analysis and Filter Design. New York: Springer, 2001.

[3] J. C. C4.07/Cired, "POWER QUALITY INDICES AND OBJECTIVES," Cigre, 2004

[4] "IEEE Recommended Practices and Requirements for Harmonic Control in Electrical Power Systems," IEEE 519:1992, 1993.

[5] M. T. Au, "STOCHASTIC MODELLING AND MITIGATION OF HARMONICS IN DISTRIBUTION NETWORKS," PhD, University of Manchester, Manchester, 2005.

[6] W. Fei, J. L. Durate and M. A. M. Hendrix "Analysis of harmonic interactions between DG inverters and polluted grids," in Proc. 2010 IEEE International Energy Conference and Exhibition (EnergyCon), 2010, pp. 194-199.

[7] D. Patel, R. K. Varma, R. Seethapathy, and M. Dang "Impact of wind turbine generators on network resonance and harmonic distortion," in Canadian Conference on Electrical and Computer Engineering (CCECE), 2010 23rd, 2010, pp. 1-6.

[8] M. T. Arif, A. M. T. Oo, A. S. Ali and G. Shafiullah "Impacts of storage and solar photovoltaic on the distribution network," in 22nd Australasian Universities Power Engineering Conference (AUPEC) 2012, 2012, pp. 1-6.

[9] "IEC 61000-3-6:1996 - Assessment of Emission Limits for Distorting Loads in MV and HV Power Systems," IEC Std, 1996.

[10] "IEC 61000-4-30 Power Quality Measurement methods," IEC Std, 2003.

[11] S. Bahadoorsingh, J. V. Milanovic, Z. Yan, C. P. Gupta, and J. Dragovic "Minimization of Voltage Sag Costs by Optimal Reconfiguration of Distribution Network Using Genetic Algorithms," IEEE Trans. Power Delivery, vol. 22, pp. 22712278, 2007.

[12] J. V. Milanovic and L. Jingwei "Application Of artificial immune system for detecting overloaded lines and voltage collapse prone buses in distribution network," in PowerTech, 2009 IEEE Bucharest, 2009, pp. 1-7.

[13] Y. Zhang, "Techno-economic Assessment of Voltage Sag Performance and Mitigation," PhD, University of Manchester, Manchester, 2008.

[14] Y. Baghzouz and O. T. Tan, "Probabilistic Modeling of Power System Harmonics," IEEE Trans. Industry Applications, vol. IA-23, pp. 173-180, 1987.

[15] The University of Edinburgh, "Matching Renewable Electricity Generation With Demand" Scottish Executive, Edinburgh 2006.

[16] N. R. E. Laboratory. (2014, 28/4/2014). PVWatts Viewer. Available:

http://gisatnrel.nrel.gov/PVWatts_Viewer/index.html

[17] S. S. Technology. (2014). EN 50438 Type certification test result sheet. Available: http://files.sma.de/d1/1366/TR50438_SBWBTLZEEN113310.pdf 